\title{
Bioclimatic Zones of Australia*
}

\section{By Dr. J. Davidson, Waite Research Institute, University of Adelaide}

$\mathrm{T}$ EMPERATURE and moisture are the chief factors affecting the physical environment of terrestrial plants and animals. In association with soil type, they exert a dominating influence on geographic distribution and seasonal abundance. In Australia, moisture is the chief limiting factor; temperatures during winter are moderate, the mean for the coldest month being above $43^{\circ} \mathrm{F}$., except in parts of Tasmania and the highlands of Victoria and New South Wales. The essential elements of climate, on which the availability of moisture depends, are precipitation and atmospheric humidity ; loss of moisture by evaporation influences the effectiveness of precipitation.

During recent years, attempts have been made by various workers in elimatology to develop a formula by means of which the efficiency of rainfall may be assessed in relation to the moisture requirements of plants and animals. These investigators have taken into account the influence of temperature and atmospheric humidity on the rate of evaporation from an exposed surface. The simplest formula is the ratio proposed by A. Meyer in 1926, in which precipitation is related to evaporation by dividing annual values for rainfall by appropriate values for atmospheric water vapour saturation deficit, both expressed in inches or centimetres. Annual values for these elements are inadequate for bioclimatic studies, particularly in Australia, owing to the seasonal character of the rainfall and its unreliability over the greater part of the continent.

It is recognized that the best index to the relationship between climate and moisture at the soil surface is the ratio of precipitation to evaporation, the critical value being $P / E=1$; with decreasing values dryness increases, with increasing values wetness increases. Unfortunately, suitable records for evaporation are available at comparatively few stations.

Where adequate data for temperature, rainfall, atmospheric humidity and evaporation are available they can be used to interpret the moisture and temperature 'conditions' in the environment of plants and animals. From the point of view of ecology, zones in which the essential elements of climate can be assessed in this respect may be defined as 'bioclimatic zones'. The flora and

- This article gives the chief features of a series of four papers by the author dealing with certain aspects of bioclimatology (Trans. Roy Soc. S. Aust. 1934-1936); under the same title, it formed the subject of a paper given at the Auckland (1936) meeting of the A.N.Z. Ass. Adv. Sci. (Section D, Zoology). fauna of the different zones may be related to similar or different environments. This emphasizes the significance of environment, in contrast with the conception of phylogenetic grouping of animals, implied in the boundaries of the faunal regions of the world as defined by Alfred Russel Wallace. The term 'bioclimatic zone' was used by A. D. Hopkins (1921), who considered temperature to be the most trustworthy guide to the range of the zones. Experimental work since that time has abundantly demonstrated that temperature alone does not give a true index to the effect of climate on the flora and fauna of an area; the index must express the effect of moisture and temperature working in combination.

I employed the Meyer formula as a monthly ratio $(P / S d)$ in order to assess the degree of wetness or dryness over Australia, month by month. For this purpose, $P / S d$ was interpreted in terms of evaporation, $(P / E)$ by reference to records for evaporation at the capital cities. Values for $P / E$ were computed for 235 stations in the Commonwealth. The continent was divided into areas showing the areas and months in which values for $P / E$ are greater or less than 0.5 ; the value 0.5 was selected tentatively as the minimum value, below which adequate moisture will not be available for general plant growth. The areas were grouped to form the five moisture zones defined in Fig. 1. For each of these zones it is known how many consecutive months have values for $P / E$ greater than $0 \cdot 5$.

The intensity of dryness in any zone depends upon the number of consecutive months that values for $P / E$ are less than $0 \cdot 5$, together with the value of the ratio. The intensity of wetness in any zone depends upon the number of consecutive months in which values for $P / E$ are greater than 0.5 , and the value of the ratio. In the central portion of Fig. 1, values for $P / E$ are less than 0.5 for every month of the year ; the region is classed as an ecological 'desert', the vegetation is characterized by acacia - semi-desert, shrub steppe and porcupine grass climax associations. The boundaries of this region, as shown in Fig. 1, differ somewhat from those obtained by employing the climatic relationships of desert areas as interpreted by Köppen (1923). The arid regions are defined as having one to six consecutive months in which $P / E$ exceeds 0.5 ; they have been grouped to form the arid and semi-arid zones. The humid regions are defined as having seven to twelve consecutive 
months in which $P / E$ exceeds 0.5 ; they have been grouped to form the semi-humid and humid zones. It is of interest to note the small area of Australia, north of the Tropic of Capricorn, which falls in the humid zone.

The temperature zones have been defined on the following basis :

A. Hot - the mean annual temperature exceeds $70^{\circ} \mathrm{F}$.
The boundaries of the various zones appear to give a better fit to the actual climate in the zones than those developed by Thornthwaite (1933), who assessed "precipitation effectiveness" by evaluating the $P / E$ ratio from data for rainfall and temperature.

There is a close agreement between the bioclimatic zones shown in Fig. 1 and the distribution of types of native vegetation; also there is a

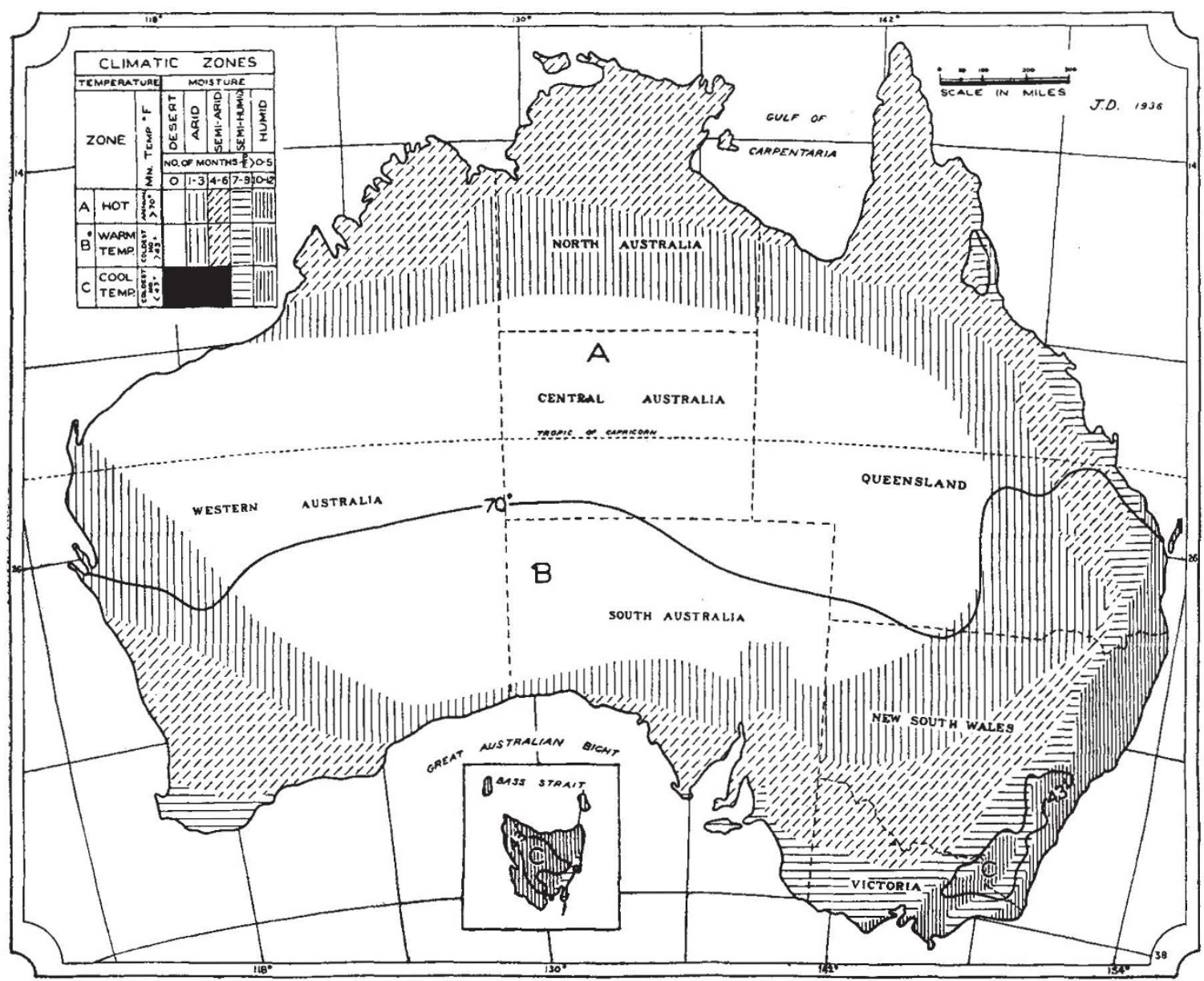

Fig. 1 .

B. Warm Temperate-the mean temperature for the coldest month does not fall below $43^{\circ} \mathrm{F}$.

$C$. Cool Temperate-the mean monthly temperature may fall below $43^{\circ} \mathrm{F}$. during one to five months of the year.

In local areas at high elevations in Zone $C$, the average monthly temperature may fall below $43^{\circ} \mathrm{F}$. for more than five months; these areas may be classed as having a cold climate.

The methods described above give a good index to the climate in the different zones; improvement in detail will be obtained when allowance can be made for the influence of additional factors affecting evaporation, such as air movements. correlation between these zones and the distribution of areas where particular agricultural crops are grown, and the sheep and cattle carrying capacity of the pastoral country. This has an important bearing on the question of settlement in Australia. The methods may be useful as a means of obtaining an estimate of the potential population of the Commonwealth, on the basis of land utilization and production.

It is easier to assess the influence on plants, than on animals, of the physical environment as determined by climate. This is particularly so with active vertebrates which can readily move away from adverse local conditions. 